\section{New genetics and diagnosis of childhood B-cell precursor acute lymphoblastic leukemia}

\section{Christine Harrison}

Northern Institute for Cancer Research, Newcastle University, Newcastle, UK

\section{Abstract}

Over the last 50 years, while significant advances have been made in the successful treatment of childhood leukaemia, similar progress has been made in understanding the genetics of the disease. In childhood B-cell precursor acute lymphoblastic leukaemia (BCP-ALL), the incidences of individual chromosomal abnormalities are well established and cytogenetics provides a reliable tool for risk stratification for treatment. In spite of this role, a number of patients will relapse. Increasing numbers of additional genetic changes, including deletions and mutations, are being discovered. Their associations with established cytogenetic subgroups and with each other remain unclear. Whether they have a link to outcome is the most important factor in terms of refinement of risk factors in relation to clinical trials. For a number of newly identified abnormalities, appropriately modified therapy has significantly improved outcome. Alternatively, some of these aberrations are providing novel molecular markers for targeted therapy.

\section{Introduction}

In childhood B-cell precursor acute lymphoblastic leukaemia (BCP-ALL), the incidences of individual chromosomal abnormalities are well established, with high hyperdiploidy and the translocation, $\mathrm{t}(12 ; 21)(\mathrm{p} 13 ; \mathrm{q} 22)$, together comprising more than $50 \%$ of cases. Other abnormalities, for example the translocation, $\mathrm{t}(9 ; 22)(\mathrm{q} 34 ; \mathrm{q} 11)$, and rearrangements of the $M L L$ gene, are rare in childhood BCP-ALL. It is also known that the distribution of chromosomal changes varies according to age, with teenagers and young adults having the highest incidence of ill-defined abnormalities. ${ }^{1}$ Particularly in BCP-ALL, chromosomal abnormalities remain strong independent indicators of risk of relapse. ${ }^{2}$

\section{Structural chromosomal abnormalities in BCP-ALL}

Those structural abnormalities with the most significant impact for risk stratification for treatment are $\mathrm{t}(9 ; 22)(\mathrm{q} 34 ; \mathrm{q} 11) / B C R-A B L 1$ and rearrangements of the $M L L$ gene. In par- ticular this applies to $\mathrm{t}(4 ; 11)(\mathrm{q} 21 ; \mathrm{q} 23) / M L L$ $A F F 1$ (previously known as MLL-AF4). The prognosis of the other $M L L$ partners may become significant in the future, particularly among infants. ${ }^{3}$ The detection of these two abnormalities provides the basic criteria for the classification of high risk groups, which is applicable to all treatment protocols. Other significant structural abnormalities include $\mathrm{t}(12 ; 21)(\mathrm{p} 13 ; \mathrm{q} 22) / E T V 6-R U N X 1$ fusion, as well as $\mathrm{t}(1 ; 19)$ (q23;p13.3)/TCF3-PBX1 fusion. However, these are not used in risk stratification on all protocols. The ETV6-RUNX1 fusion occurs in approximately $25 \%$ of younger children with BCP-ALL. These patients have an extremely good prognosis Among patients with TCF3 rearrangements, those with TCF3-PBX1 were originally regarded as poor risk on some treatment protocols, but on modern therapy they are classified as standard risk. 4,5 In contrast, the rare variant, $\mathrm{t}(17 ; 19)(\mathrm{q} 22 ; \mathrm{p} 13) / H L F$ TCF3 fusion, has a dismal outcome on all therapies. ${ }^{6}$ Thus its accurate identification is important.

\section{Numerical chromosomal abnormal- ities in BCP-ALL}

Significant numerical abnormalities include high hyperdiploidy (51-65 chromosomes), ${ }^{7}$ nearhaploidy (24-29 chromosomes) and low hypodiploidy (31-39 chromosomes)..$^{8,9}$ High hyperdiploidy accounts for approximately $30 \%$ of childhood BCP-ALL and is characterised by the gain of specific chromosomes. It is associated with a good prognosis in children. Near-haploidy and low hypodiploidy are rare, comprising $<1 \%$ each of childhood ALL. Their characteristic features are the gain of specific chromosomes onto the haploid chromosome set and, in the majority of patients, the presence of a population of cells with an exact doubling of this chromosome number. ${ }^{8}$ Both are linked to a poor outcome and are used to stratify patients as high risk.

\section{Submicroscopic abnormalities in BCP-ALL}

A significant discovery was the finding that the disruption of genes involved in B-cell development played an important role in leukaemogenesis in childhood BCP-ALL. ${ }^{10}$ Approximately $40 \%$ of these patients had abnormalities of genes involved in the B-cell developmental pathway: PAX5, TCF3, EBF1, LEF1, $I K Z F 1$ and IKZF3. Other genes frequently affected were those controlling cell cycle progression: CDKN2A, CDKN1B and RB1.11,12 Many of these deletions can be detected by FISH and/or genomic arrays. Whether there is a link between these genes and outcome has become a critical question. ${ }^{13}$ In particular, the association of IKZF1 deletions with a poor prognosis ${ }^{14,15}$ requires further validation in prospective, independent and unselected trialbased patient cohorts.
Correspondence: Leukaemia Research Cytogenetics Group, Sir James Spence Institute, Royal Victoria Infirmary, Queen Victoria Road, Newcastle upon Tyne, NE1 4LP.

Tel: +44 (0) 1912821320 - Fax: +44 (0) 1912821326

E-mail: christine.harrison@ncl.ac.uk

Key words: childhood B-cell precursor acute lymphoblastic leukemia.

Received for publication: 4 May 2011. Accepted for publication: 4 June 2011.

This work is licensed under a Creative Commons Attribution NonCommercial 3.0 License (CC BYNC 3.0).

(C) Copyright C. Harrison, 2011

Licensee PAGEPress, Italy

Pediatric Reports 2011; 3(s2):e4

doi:10.4081/pr.2011.s2.e4

What can be the impact of discovering a new genetic abnormality?

Intrachromosomal amplification of chromosome 21- iAMP21

The cytogenetic subgroup, iAMP21 (intrachromosomal amplification of chromosome 21 ), was identified during routine screening for the presence of the ETV6-RUNX1 fusion by fluorescence in situ hybridization (FISH). ${ }^{16,17}$ Patients are negative for the ETV6-RUNX1 fusion, while in addition to the two normal copies of the ETV6 signal, show multiple RUNX1 signals (3 or more additional signals) with this probe. In metaphase, one signal is located to the normal chromosome 21, while the others are seen in tandem duplication along an abnormal chromosome 21.18 In interphase, the signals are clustered together, except for one signal representing the normal chromosome 21 , which is usually located apart. Cytogenetics, multiple colour FISH and high resolution genomic arrays have shown that the morphology of the abnormal chromosome 21 is highly variable between patients, with multiple, complex genomic rearrangements, and that the commonly amplified region always includes the RUNX1 gene.18-20 This abnormality was originally described as poor risk on standard therapy, ${ }^{17,18,21,22}$ although the outcome has since been shown to be protocol dependent.23,24 Thus its accurate detection is important to guide therapy, at least in some protocols. Currently FISH with probes directed to RUNX1 remain the only reliable detection method. Studies are continuing to determine the mechanism(s) underlying this unusual abnormality in order to develop an improved diagnostic test. 


\section{IGH@ translocations}

Translocations involving IGH@ at 14q32 are emerging as a significant subgroup in childhood BCP-ALL, at an incidence of approximately 8\%. Translocations involving IGH@ with five genes from the $C E B P$ gene family, ID4 and the cytokine receptor to erythropoietin, $E P O R$, have recently been described. ${ }^{25-28}$ It is of interest that they occur more frequently in adolescents and, although numbers are small, they appear to have an inferior outcome.

Recently, a cryptic translocation, $\mathrm{t}(\mathrm{X} ; 14)$ (p22;q32) or t(Y;14)(p11;q32), involving IGH@ and CRLF2 in the pseudoautosomal region (PAR1) of the sex chromosomes, ${ }^{29}$ and a deletion within PAR1, giving rise to the P2RY8CRLF2 fusion, have been reported.29-32 They lead to overexpression of CRLF2 at both the transcript and protein levels, which has been defined as a novel, significant abnormality in BCP-ALL. CRLF2 alterations, including activating mutations of the $C R L F 2$ receptor itself, are associated with activating $J A K$ mutations resulting in constitutive activation of the JAKSTAT signalling pathway and they are particularly common in Down syndrome ALL. . $9,31-33^{-3}$ Activation of this pathway has been associated with a worse prognosis in adults and children in some trials, 34,35 although not in others. ${ }^{36}$ Nevertheless, it has been highlighted as an important consideration for targeted therapy. Following further validation, the detection of CRLF2 alterations may become a necessary diagnostic test.

In childhood ALL, interest in mutations within genes involved in key cellular pathways is heightening as deep-sequencing techniques are becoming established. ${ }^{37}$ A number of associations with other genetic changes are already known, such as the link between mutations of genes within the RAS signalling pathway and high hyperdiploidy. ${ }^{38,39}$ The difficulty lies in unravelling the relationships between the expanding numbers of abnormalities. It is likely that whole genome sequencing approaches to detect submicroscopic rearrangements together with mutations will become more commonplace within the arena of genetic research within the near future.

Current research is directed towards determining the prognostic significance of the recently described genomic abnormalities on the background of established aberrations with the aim of predicting all patients at risk of relapse. The task is not simple due to the ever increasing numbers of all types of lesions and the complexity of their interactions. However, the goal to be achieved in the near future is to generate a personal genetic profile for each patient from which appropriate molecular targets will emerge, leading to the provision of individualised treatment with reduced morbidity and further improved outcome.

\section{References}

1. Harrison CJ. Cytogenetics of paediatric and adolescent acute lymphoblastic leukaemia. Br J Haematol 2009;144:147-56.

2. Moorman AV, Ensor HM, Richards SM, et al. Prognostic effect of chromosomal abnormalities in childhood B-cell precursor acute lymphoblastic leukaemia: results from the UK Medical Research Council ALL97/99 randomised trial. Lancet Oncol 2010;11:429-38.

3. Pieters R, Schrappe M, De LP, et al. A treatment protocol for infants younger than 1 year with acute lymphoblastic leukaemia (Interfant-99): an observational study and a multicentre randomised trial. Lancet 2007;370:240-50.

4. Pui CH, Raimondi S, Hancock ML, et al. Immunologic, cytogenetic, and clinical characterization of childhood acute lymphoblastic leukemia with the $t(1 ; 19)(q 23 ; p 13)$ or its derivative. J Clin Oncol 1994;12:2601-6.

5. Kager L, Lion T, Attarbaschi A, et al. Incidence and outcome of TCF3-PBX1-positive acute lymphoblastic leukemia in Austrian children. Haematologica 2007;92:1561-4.

6. Hunger SP. Chromosomal translocations involving the E2A gene in acute lymphoblastic leukemia: clinical features and molecular pathogenesis. Blood 1996;87:1211-24.

7. Moorman AV, Richards SM, Martineau M, et al. Outcome heterogeneity in childhood high-hyperdiploid acute lymphoblastic leukemia. Blood 2003;102:2756-62.

8. Harrison CJ, Moorman AV, Broadfield ZJ, et al. Three distinct subgroups of hypodiploidy in acute lymphoblastic leukaemia. $\mathrm{Br} \mathrm{J}$ Haematol 2004;125:552-559.

9. Nachman JB, Heerema NA, Sather H, et al. Outcome of treatment in children with hypodiploid acute lymphoblastic leukemia. Blood 2007;110:1112-5.

10. Mullighan CG, Goorha S, Radtke I, et al. Genome-wide analysis of genetic alterations in acute lymphoblastic leukaemia. Nature 2007;446:758-64.

11. Kuiper RP, Schoenmakers EF, van Reijmersdal SV, et al. High-resolution genomic profiling of childhood ALL reveals novel recurrent genetic lesions affecting pathways involved in lymphocyte differentiation and cell cycle progression. Leukemia 2007;21:1258-66.

12. Strefford JC, Worley H, Barber K, et al. Genome complexity in acute lymphoblastic leukemia is revealed by array-based comparative genomic hybridization. Oncogene 2007;26:4306-18.

13. Den Boer ML, van Slegtenhorst M, De Menezes RX, et al. A subtype of childhood acute lymphoblastic leukaemia with poor treatment outcome: a genome-wide classi- fication study. Lancet Oncol 2009;10:125-34.

14. Mullighan CG, Su X, Zhang J, et al. Deletion of IKZF1 and prognosis in acute lymphoblastic leukemia. N Engl J Med 2009; 360:470-80.

15. Kuiper RP, Waanders E, van der Velden VH, et al. IKZF1 deletions predict relapse in uniformly treated pediatric precursor BALL. Leukemia 2010;24:1258-64.

16. Harrison CJ, Moorman AV, Barber KE, et al. Interphase molecular cytogenetic screening for chromosomal abnormalities of prognostic significance in childhood acute lymphoblastic leukaemia: a UK Cancer Cytogenetics Group Study. Br J Haematol 2005;129:520-30.

17. Soulier J, Trakhtenbrot L, Najfeld V, et al. Amplification of band q22 of chromosome 21, including AML1, in older children with acute lymphoblastic leukemia: an emerging molecular cytogenetic subgroup. Leukemia 2003;17:1679-82.

18. Harewood L, Robinson H, Harris R, et al. Amplification of AML1 on a duplicated chromosome 21 in acute lymphoblastic leukemia: a study of 20 cases. Leukemia 2003;17:547-53.

19. Robinson HM, Harrison CJ, Moorman AV, et al. Intrachromosomal amplification of chromosome 21 (iAMP21) may arise from a breakage-fusion-bridge cycle. Genes Chromosomes Cancer 2007;46:318-26.

20. Strefford JC, Van Delft FW, Robinson HM, et al. Complex genomic alterations and gene expression in acute lymphoblastic leukemia with intrachromosomal amplification of chromosome 21. Proc Natl Acad Sci USA 2006;103:8167-72.

21. Robinson HM, Broadfield ZJ, Cheung KL, et al. Amplification of AML1 in acute lymphoblastic leukemia is associated with a poor outcome. Leukemia 2003;17:2249-50.

22. Moorman AV, Richards SM, Robinson HM, et al. Prognosis of children with acute lymphoblastic leukemia (ALL) and intrachromosomal amplification of chromosome 21 (iAMP21). Blood 2007;109:2327-30.

23. Attarbaschi A, Mann G, Panzer-Grumayer $\mathrm{R}$, et al. Minimal residual disease values discriminate between low and high relapse risk in children with B-cell precursor acute lymphoblastic leukemia and an intrachromosomal amplification of chromosome 21: the Austrian and German acute lymphoblastic leukemia Berlin-FrankfurtMunster (ALL-BFM) trials. J Clin Oncol 2008;26:3046-50.

24. Heerema NA, Carroll AJ, Borowitz MJ, et al. Amplification of AML1 Does Not Impact Early Outcome of Children with Acute Lymphoblastic Leukemia (ALL) Treated with Risk-Directed Chemotherapy: A Report From the Children's Oncology Group (COG). ASH Annual Meeting and Exposi- 
tion 2009;poster board II-574.

25. Akasaka T, Balasas T, Russell LJ, et al. Five members of the CEBP transcription factor family are targeted by recurrent IGH translocations in B-cell precursor acute lymphoblastic leukemia (BCP-ALL). Blood 2007;109:3451-61.

26. Chapiro E, Russell L, Radford-Weiss I, et al. Overexpression of CEBPA resulting from the translocation $\mathrm{t}(14 ; 19)(\mathrm{q} 32 ; \mathrm{q} 13)$ of human precursor B acute lymphoblastic leukemia. Blood 2006;10:3560-3.

27. Russell LJ, Akasaka T, Majid A, et al. $\mathrm{t}(6 ; 14)(\mathrm{p} 22 ; \mathrm{q} 32)$ : a new recurrent IGH@ translocation involving ID4 in B-cell precursor acute lymphoblastic leukemia (BCP-ALL). Blood 2008;111:387-91.

28. Russell LJ, De Castro DG, Griffiths M, et al. A novel translocation, $\mathrm{t}(14 ; 19)(\mathrm{q} 32 ; \mathrm{p} 13)$, involving IGH@ and the cytokine receptor for erythropoietin. Leukemia 2009;23:614-7.

29. Russell LJ, Capasso M, Vater I, et al. Deregulated expression of cytokine receptor gene, CRLF2, is involved in lymphoid transformation in B-cell precursor acute lymphoblastic leukemia. Blood 2009;114:2688-98.

30. Mullighan CG, Collins-Underwood JR, Phillips LA, et al. Rearrangement of CRLF2 in B-progenitor- and Down syndrome-associated acute lymphoblastic leukemia. Nat Genet 2009;41:1243-6.

31. Hertzberg L, Vendramini E, Ganmore I, et al. Down syndrome acute lymphoblastic leukemia: a highly heterogeneous disease in which aberrant expression of CRLF2 is associated with mutated JAK2: a report from the iBFM Study Group. Blood 2010;115:1006-17.

32. Yoda A, Yoda Y, Chiaretti S, et al. Functional screening identifies CRLF2 in precursor B-cell acute lymphoblastic leukemia. Proc Natl Acad Sci U S A 2009;107:252-7.

33. Chapiro E, Russell L, Lainey E, et al. Activating mutation in the TSLPR gene in Bcell precursor lymphoblastic leukemia. Leukemia 2010;24:642-5.

34. Harvey RC, Mullighan CG, Chen IM, et al. Rearrangement of CRLF2 is associated with mutation of JAK kinases, alteration of IKZF1, Hispanic/Latino ethnicity, and a poor outcome in pediatric B-progenitor acute lymphoblastic leukemia. Blood 2010;115:5312-21.

35. Cario G, Zimmermann M, Romey R, et al. Presence of the P2RY8-CRLF2 rearrangement is associated with a poor prognosis in non-high-risk precursor B-cell acute lymphoblastic leukemia in children treated according to the ALL-BFM 2000 protocol. Blood 2010;115:5393-7.

36. Ensor HM, Schwab C, Russell LJ, et al. Demographic, clinical and outcome features of children with acute lymphoblastic leukemia and CRLF2 deregulation: results from the MRC ALL97 clinical trial. Blood 2011;117:2129-36.

37. Zhang J, Mullighan CG, Harvey RC, et al. Mutations in the RAS Signaling, B-Cell Development, TP53/RB1, and JAK Signaling Pathways Are Common in High Risk B-Precursor Childhood Acute Lymphoblastic Leukemia (ALL): A Report From the Children's Oncology Group (COG) High-Risk (HR) ALL TARGET Project. ASH Annual Meeting and Exposition 2009.

38. Case M, Matheson E, Minto L, et al. Mutation of genes affecting the RAS pathway is common in childhood acute lymphoblastic leukemia. Cancer Res 2008;68:6803-9.

39. Paulsson K, Horvat A, Strombeck B, et al. Mutations of FLT3, NRAS, KRAS, and PTPN11 are frequent and possibly mutually exclusive in high hyperdiploid childhood acute lymphoblastic leukemia. Genes Chromos Canc 2008;47:26-33. 